\section{The role of public and private social support in reducing conformity}

\author{
BARRY W. E. BRAGG, University of Toronto, Toronto, Ont., Canada \\ and \\ VERNON L. ALLEN, University of Wisconsin, Madison, Wis. 53706
}

Ss were given public social support, private social support, or subsequent public social support after, in each case, having been the first person to dissent publicly from the group. All three types of social support were equally effective in reducing conformity relative to a unanimous group. Results suggest that interpersonal factors are not crucial in explaining independence produced by a social supporter; rather, effectiveness of the social supporter may lie in his providing an independent confirmation of social and physical reality.

The social support effect, first demonstrated by Asch (1951), has been well documented (Allen \& Levine, 1968, 1969; Kiesler, Zanna, \& De Salvo, 1966; Malof \& Lott, 1962). The presence of one group member who agrees with the $S$ significantly decreases the amount of conformity in a group pressure situation. Allen \& Levine (1971) have suggested three possible explanations for the effectiveness of social support: (1) breaking group consensus, (2) independent assessment of reality, and (3) preventing social isolation.

Allen \& Levine $(1968,1969)$ provide data consistent with their contention that independence produced by the presence of a partner cannot be explained satisfactorily in terms of another person's merely breaking the group's consensus. One person's disagreeing with the group by giving any answer at all does not automatically free the $\mathrm{S}$ from group pressure in general.

The hypothesis that the social supporter's effectiveness is due to his providing an independent assessment of social and physical reality has received some empirical support (Allen \& Levine, 1971). Nevertheless, other factors of a more interpersonal and social nature may also contribute to the effectiveness of social support as a means of reducing conformity. The present experiment provides data relevant to the third explanation mentioned above, social isolation.

In previous research, the social supporter has always responded publicly before it was the S's turn to answer. Two factors are involved in this public social support situation: (1) the $\mathrm{S}$ forms a coalition publicly with the supporter, i.e., the $S$ is not alone in opposing the group, and (2) the social supporter is the first person to disagree publicly with the group.

Data from other research on group process suggest that publicness of the social supporter's responses may be an conformity. Being alone in opposition to the group frequently has negative consequences for the dissenter. A lone $S$ who publicly disagrees with the group expects to be rejected (Gerard \& Rotter, 1961); and a considerable amount of data indicates that the group does often respond with hostility toward an attitudinal deviate (Sampson \& Brandon, 1964; Schachter, 1951). Thus, private social support, which would leave the individual publicly all alone if he dissented from the group, might fail to reduce conformity. On the other hand, if the social supporter's effectiveness is due to his providing an independent assessment of physical and social reality (Allen \& Levine, 1971), then private social support should be sufficient to reduce conformity.

The second important aspect of the public social support situation is that the partner breaks the group consensus first, before it is the S's turn to answer. The first person to disagree with the group is likely to be perceived as responsible for the dissent of anyone following him; thus, the first dissenter would be the primary recipient of the group's typically negative reactions toward a deviate. Therefore, independence might not occur when the $\mathrm{S}$ responds publicly prior to the social supporter's turn to answer publicly, even though the $S$ is aware at the time of answering that the social supporter actually agrees with him.

\section{DESIGN}

A 4 by 2 by 2 analysis of variance design was used, consisting of the following factors: experimental condition (consensus, public social support, private social support, dissent-first), sex of $\mathrm{S}$ (male, female), and type of item (visual, opinion). SUBJECTS

Eighty Ss (40 males and 40 females) from introductory psychology classes participated in the experiment. Ten males and 10 females were assigned important factor in the reduction of randomly to the four experimental conditions. Postexperimental interviews disclosed that 5 Ss ( 2 males and 3 females) had prior knowledge of the deception, so they were removed from the analysis.

\section{APPARATUS}

The apparatus was a Crutchfield-type conformity apparatus (Crutchfield, 1955). It consists of five communication panels located in visually isolated booths, a master control panel, and a remote control slide projector. The Ss' panels displayed five rows of lights indicating nine possible response alternatives. To communicate his answer, the $\mathrm{S}$ closed one of the nine switches in his panel. The responses ostensibly coming from the other Ss were, in fact, controlled by the $\mathrm{E}$; every $\mathrm{S}$ actually answered in the fifth position.

\section{STIMULI}

The task for the $\mathbf{S}$ consisted of making judgments on 46 items. Twenty-three of these were visual items (e.g., estimating which of nine lines was the same length as a comparison line) and 23 were opinion items (e.g., "I think most people get too much education"). On opinion items, the $S$ used a 9-point scale ranging from "very strongly agree" to "very strongly disagree."

Ten of the 23 items of each type were "test" items on which group pressure was applied. On test items, the $S$, answering in the fifth position, observed incorrect or unpopular (simulated) responses from the other four group members. The remaining 13 items of each type were "filler" items on which the $S$ received correct or popular answers from the simulated group. Only "test" items were scored for conformity.

Conformity scores were calculated by summing the differences between the model or correct answer and the $S$ 's response in the conformity situation. These sums were then divided by the number of items. Means presented in the results section represent average amount of change per person per item.

EXPERIMENTAL CONDITIONS

In the consensus condition, the $\mathrm{S}$ was confronted with a unanimous group giving incorrect or unpopular answers on all test items. In the public social support condition, three simulated persons gave incorrect answers on test items, and the person in the fourth position gave the correct, or model, response. In the private social support condition, the $\mathrm{S}$-but not the group-could see the answers of the person answering fourth. During practice trials at the beginning of the experiment, alleged electronic failure in the apparatus was staged. When the fourth $\mathrm{S}$ responded, his answers did 
not appear on the panels of $\mathrm{Ss}$ answering in the first three positions. After pretending unsuccessfully to repair the breakdown, the $E$ stated that the experiment would continue although only person five could see the answers of the person answering fourth in turn. Ss were then assigned to their answering positions and, of course, every $\mathbf{S}$ was assigned to the fifth (last) position. In the consensus and public social support conditions, the breakdown was staged also but quickly repaired. In the dissent-first condition, when the alleged breakdown could not be repaired, the $E$ said he would announce the answers of the fourth person after each trial. As in the private social support condition, the $S$ could see the answers of the fourth person; however, the $S$ knew that the other group members saw him as being the first person publicly to disagree with the group.

Answers of the social supporter were identical in the public social support, private social support, and dissent-first conditions. In all conditions, instructions described the experiment as concerned with the formation of impressions of other persons on the basis of limited information, so announcing the fourth person's answers in the dissent-first condition seemed reasonable. These instructions should have increased the normative pressure of the group. PROCEDURE

Five same-sex Ss were tested simultaneously. Instructions described the experiment as concerned with the study of impression formation when only limited information is available. Operation of the apparatus was explained. A series of three practice trials followed, during which Ss actually were assigned to different answering positions and saw the true answers of their fellow Ss. Answers were called out aloud during the practice trials to enhance credibility. During the third practice trial, the pretended electronic failure in the apparatus occurred. At the end of the experiment, Ss filled out a postexperimental questionnaire and were thoroughly debriefed.

\section{RESULTS}

Analysis of variance on conformity scores disclosed a significant main effect for conditions $(\mathrm{F}=3.88, \mathrm{df}=$ $3 / 68, \quad \mathrm{p}<.05)$ and no significant interactions. Data were combined across sex for further analysis, since no sex differences were found in the analysis of variance.

The highest mean level of conformity was observed in the consensus condition (.979), as would be expected. Relative to the consensus condition, conformity was lower in each of the three social support conditions: .584 for public social support, .455 for private social support, and .327 for dissent first.

Subsequent tests were conducted to compare the amount of conformity in the three social support conditions to the consensus condition. Conformity showed a significant decrease relative to the consensus condition in the public social support $(\mathrm{p}<.05)$, private social support $(\mathbf{p}<.01)$, and dissent-first $\quad(p<.01) \quad$ conditions. There were no significant differences in the level of conformity among the three social support conditions. Thus, the Ss were independent in the private social support and dissent-first conditions, as well as in the public social support condition, in which independence typically has been found in previous research.

\section{DISCUSSION}

The present experiment was designed to test two aspects of the social or interpersonal explanation for the effectiveness of the social supporter in reducing conformity: First, the social supporter may be effective because his responses are public, thus preventing social isolation of the $S$; and second, the social supporter may be effective because he is the first person to dissent publicly from the group and should be perceived as the principal recipient of any negative reactions from the group. Neither aspect of the interpersonal explanation received support from results of the present experiment. Level of conformity was significantly reduced in all three social support conditions, with no difference being found between public and private social support.

We can conclude, then, that whether or not the S perceives that the group knows that someone else agrees with him is apparently not a crucial factor. The $S$ is independent when he has social support, regardless of its public or private nature. Present results suggest, therefore, that social or interpersonal factors are less important than cognitive factors in producing the independence associated with social support. No more than the mere knowledge of agreement from another person seems to be essential to elicit nonconformity.

It must be emphasized, however, that this conclusion should not be generalized too freely. Our results may be limited to the group pressure procedure employed in the present experiment, which probably has a strong "informational pressure" component. But the "impression formation" instructions used should have increased the degree of "normative pressure" from the group by making salient affiliation and self-presentation motives. So it cannot be claimed that the present situation did not contain a substantial normative or social component.

What, then, is the basic factor underlying the effectiveness of social support in reducing conformity: Allen $\&$ Levine (1971) have argued that the independent assessment of reality-physical and social reality-by another person is a crucial factor. Other data show that the removal of a social supporter from the group does not eliminate the S's nonconformity (Bragg, 1971), suggesting that the constant independent assessment of reality by the partner on every trial is not a necessary condition for independence to persist. It would seem fair to suggest that independent assessment of reality is, at the very least, an important factor leading to the initial independence associated with the presence of a social supporter. The finding of the present experiment underlines the relative unimportance of social or interpersonal factors and points strongly toward the importance of cognitive factors-such as the role of the partner in providing information about reality-as the underlying mechanism responsible for eliciting nonconformity in the presence of a social supporter.

\section{REFERENCES}

ALLEN, V. L., \& LEVINE, J. M. Social support, dissent, and conformity. Sociometry, 1968, 31, 138-149.

ALLEN, V. L., \& Le'VINE, J. M. Consensus and conformity. Journal of Experimental Social Psychology, 1969, 5, 389-399.

ALLEN, V. L., \& LEVINE, J. M. Social support and conformity: The role of independent assessment of reality. Journal of Experimental Social Psychology, 1971, 7, 48-58.

ASCH, S. E. Effects of group pressure upon modification and distortion of judgments. In H. Guetzkow (Ed.), Groups, leadership and men. Pittsburgh: Carnegie Press, 1951. Pp. 177-190.

BRAGG, B. W. E. Resistance of conformity pressure without social support. Proceedings, 79th Annual Convention, American Psychological Association, 1971. Pp. 363-364.

CRUTCHFIELD, R. S. Conformity and character. American Psychologist, 1955 , 10, 191-198.

GERARD, H. B., \& ROTTER, G. S. Time perspective, consistency of attitude, and social influence. Journal of Abnormal \& Social Psychology, 1961, 62, 565-572.

KIESLER, C., ZANNA, M., \& DE SALVO, J. Deviation and conformity: Opinion change as a function of commitment attraction and presence of a deviate. Journal of Personality \& Social Psychology, 1966, 3, 458-467.

MALOF, M., \& LOTT, A. J. Ethnocentrism and acceptance of Negro support in a group pressure situation. Journal of Abnormal \& Social Psychology, 1962, 65, 25 4-258.

SAMPSON, E. S., \& BRANDON, A. The effects of role and opinion deviation on small group behavior. Sociometry, 1964, 27, 261-281.

SCHACHTER, S. Deviation, rejection, and communication. Journal of Abnormal \& Social Psychology, 1951, 46, 190-207. 